\title{
Guanxi, Weiqi and Chinese Strategic Thinking
}

\author{
Zhongqi Pan ${ }^{1}$
}

Received: 4 March 2016/Accepted: 11 March 2016/Published online: 22 March 2016

(C) Fudan University and Springer Science+Business Media Singapore 2016

\begin{abstract}
In their perceptions and preferences of Guanxi, the Chinese follow a relational way of thinking, which is in stark contrast to the American generic way of thinking. This difference lies in how Chinese and Americans behave in playing board games and engaging with others in real life. The game of Weiqi signifies the Chinese way of gaming, whereas the game of Chess denotes the Western way of gaming. Chinese strategic thinking is relational and best exemplified in the way that the Chinese perceive and deal with various Guanxi in the game of Weiqi. The Chinese prefer to define their strategic goals in relative terms, employ a combination of various means to achieve good and stable Guanxi with other countries without defining any of them, or being defined by any of them, as an enemy. The Chinese also tend to favor a flexible foreign strategy with contingent adaptation as its principle, a favorable balance of shi as its linchpin, and such shortcomings as nearsightedness, greediness and impatience as its taboos.
\end{abstract}

Keywords Guanxi $\cdot$ Weiqi $\cdot$ Strategic thinking $\cdot$ Shi

\section{Introduction}

China's strategic behaviors have been approached from different theoretical perspectives. A debate thus ensues, with some arguing that China has been very assertive since 2009, while others contend that China did not behave more assertively than before except in the cases of maritime disputes in the East and South China seas (Matsuda 2014; He and Feng 2012; Johnston 2013). The

Zhongqi Pan

zqpan@fudan.edu.cn

1 School of International Relations and Public Affairs (SIRPA), Fudan University, Shanghai, China 
disagreement challenges the neo-realist structural approach to justify why China's strategic behaviors differ from those of other countries with a similar position in the international system. On the other hand, it also challenges the strategic cultural approach to explain why there are similarities in the strategic choices made by China and the US, for example, notwithstanding their divergent strategic cultures. According to Alastair Ian Johnston (1995b), material factors in conjunction with strategic culture completely explain strategic behavior. A solution could be made by combining those two conflicting approaches together. But the question is how, if yes.

Behind strategic behavior lies strategic thinking, which could be defined as the general perception, preference and logic of inference in the process of strategy making and conducting. Strategic thinking varies from one state to another, originates from a nation state's history and culture, and remains stable and influential on people's behaviors across different periods of time. Strategic thinking is multi-faceted and plays its role in different ways to shape a nation state's strategic behaviors when it is in different positions in the international structure of power. While strategic thinking could explain why a country will behave more assertively with increased power, it could also explain why it does not. It does not assume a country is culturally bound to follow either aggressive or defensive foreign strategies as many strategic cultural scholars do (for relevant literature, see Johnston 1995a), even though culture matters in strategic thinking. This paper thus argues that the concept of strategic thinking could serve as a linkage between the neorealist structural approach and the strategic cultural approach. To understand China's strategic behaviors, a better perspective is neither China's ever-changing power position, nor its narrowly and biasedly interpreted strategic culture, but Chinese strategic thinking, which could be explored by looking into, among other things, the concept of Guanxi and the game of Weiqi that are uniquely Chinese.

Guanxi could be translated narrowly as "social connections" and "social networks" (Gold et al. 2002, 3-20) or broadly as "relations" and "relationality" (Qin 2009) to denote the interconnectivities between people and between things. As argued by Chinese philosophers, every person lives in a network of social relations, without which he cannot be identified, and his relationality to a certain natural circumstance determines his life outcomes (see, for example, Liang 1987, 79). Guanxi is essential to the Chinese way of life. And Chinese perceptions and preferences of Guanxi shape the Chinese way of thinking.

Weiqi could be translated as "a game of surrounding pieces" (Kissinger 2011, 23) or "a game of encircling territories" (Lai 2004, Endnote 4). It is often known in the West by a variation of its Japanese name, "go". Weiqi is of Chinese origin and is one of the world's oldest board games. Although the popularity of Weiqi has varied over time throughout Chinese history, it is the most important game that has shaped the Chinese way of gaming, which has broad implications for the Chinese way of thinking. With the introduction of a variety of national and international matches and tournaments, Weiqi has remarkably regained its popularity and viability in China in particular and in East Asia in general. It thus serves as an interesting tool to identify the mind-set behind China's strategic behaviors. 
In the following sections, I will examine how differently Chinese and Westerners perceive Guanxi and what this difference implies for their divergent ways of thinking. In terms of perceptions and preferences of Guanxi, the Chinese relational way of thinking is in stark contrast to the American generic way of thinking. Then, this paper will dig into the game of Weiqi to look at how the Chinese behave in playing board games and engaging with others in real life. A comparison with the game of Chess that signifies the Western way of gaming will be employed when appropriate. Further, this paper will link Guanxi and Weiqi together to explore how the Chinese perceive and deal with various Guanxi in the game of Weiqi, which sheds light on Chinese strategic thinking. Chinese strategic thinking will be framed into six elements: goals, threats, means, principles, linchpins, and taboos, the Chinese respective perceptions and preferences of which will be analyzed. The paper will conclude with a brief summary of China's preferable gaming strategy in its foreign relations.

\section{Guanxi: The Chinese Way of Thinking}

Guanxi is very important for the Chinese because it is not only key to their way of life, but also has been embedded in their way of thinking. For the Chinese, every individual subject or object must exist in certain context that is woven by various relationships, without which they even cannot be identified. The Chinese thus perceive the world from a holistic perspective and they see not just individual subjects or objects but a variety of Guanxi they involve. Only by figuring out those Guanxi, could people understand subjects or objects that apparently stand alone individually. While it is normal for every person in their perceptions to relate one thing to another, what distinguishes the Chinese way of thinking from, for example, the American way of thinking is not whether they look into Guanxi but how they perceive Guanxi, or in other words, what kind of Guanxi they find between things (for an American view, see Emirbayer 1997). By and large, the Chinese follow a relational thinking to link different things together in a kind of Guanxi that is probably not obvious to other observers. The Americans by contrast follow a generic thinking to link the same things together and ignore Guanxi between things that are different in terms of generic type.

Developmental psychologist Liang-hwang Chiu (1972) has arranged a very interesting experiment to show how differently Chinese and Americans perceive Guanxi between things. A group of Chinese children and a group of American children were asked to do grouping among three items-chicken, cow and grassaccording to their own measuring preferences. As a result, most of the Chinese children drew a line between the cow and the grass, while most of the American children linked the chicken and the cow together. Chiu found that the Chinese children preferred to group objects on the basis of Guanxi. They link the cow with the grass because "the cow eats the grass". The American children preferred to group objects according to whether they belonged to the same "taxonomic" category. In this experiment, the chicken and the cow are the same in terms of classification. 
Richard Nisbett, a Distinguished University Professor at the University of Michigan, applied the same experiment to adults and arrived at the same result. He and his assistants asked college students from the US and from China to group panda, monkey and banana by indicating which two of the three were most closely related. As a result, "The American participants showed a marked preference for grouping on the basis of common category membership: Panda and monkey fit into the animal category. The Chinese participants showed a preference for grouping on the basis of thematic relationships (e.g., monkey and banana) and justified their answers in terms of relationships: Monkeys eat bananas" (Nisbett 2003, 140-141). So Nisbett concluded that Americans use categories to classify objects more readily and more frequently than the Chinese, who prefer to describe objects in terms of relationships. Based upon many other relevant experiments, he believed that there is a big contrast between Westerners and Asians in the way of thinking. He said, "Westerners attend primarily to the focal object or person and Asians attend more broadly to the field and to the relations between the object and the field. Westerners tend to assume that events are caused by the object and Asians are inclined to assign greater importance to the context" (Nisbett 2003, 127). And this difference is primarily shaped by the geography of thought, as indicated by the title of his book.

In the same vein, Xiaotong Fei, a top Chinese sociologist, has interpreted the fundamental difference between Chinese and Western societies in terms of Guanxi, notwithstanding their many commonalities. He defined Western society as a cooperative pattern (tuanti geju), in which individuals are the basic units of society and they are united by social contracts. He analogized the individual in Western society to firewood, which could stand in isolation and be bundled in different groups and in different sizes according not to their natural social relations but negotiated social contracts. The boundary between different groups is clearly defined. Western society is thus individualistic in nature and the social order is constructed in a cooperative pattern (Fei 1985, 22). By contrast, Fei argued, Chinese society constitutes a unity-in-diversity pattern (chaxu geju), in which the basic units are not individuals but patriarchal clans, and the network of social relations is structured by the closeness of Guanxi at horizontal level and by the hierarchy of seniority at vertical level. Individuals only exist in social connections on the basis of family relations. He compared Chinese individuals in society to stones being thrown into water, with circles of ripples spreading from the center to the periphery at a decelerating speed. Ripples represent inseparable social relations by which individuals are interconnected. The farther the ripple is away from the center, the lesser the closeness of Guanxi is to the individual. People have diverse social relations, through which they make a unity. So Chinese society is familistic in nature and the social order is achieved in a unity-in-diversity pattern (Fei 1985, 25).

From a Guanxi perspective, the distinct way of thinking for the Chinese exemplifies itself not only in how the Chinese group things and make a society, but also in how they deal with their foreign relations. Brantly Womack has uniquely captured different mind-sets between Chinese and Westerners in this aspect. He refers to the Chinese way of thinking as "the logic of relationships" and the Westerners' as "the logic of transactions". The main assumption in "the logic of relationships" is that both sides are better off if they maintain a good and 
stable relationship. However, in "the logic of transactions", a normal relationship requires symmetry of partners or equality of exchanges. He thus argues that, "As China applies relationship logic to international relations, its actions aim to optimise relationships rather than transactions. In this model China does not use preponderance of power to optimise its side of each transaction, but rather to stabilise beneficial relations." For him, "This is a fundamentally different attitude from that of the modern West, which has tended to use the carpenter's rule of its own norms to level and if necessary pressurise others into uniformity" (Womack 2008, 296).

In developing their respective foreign relations, China cares more about the longterm and overall nature of its relationships with others than about China's specific benefits from every interaction, while the US follows a cost-benefit calculation in each transaction, rather than considering the long-term and overall nature of its relationships with others. China had developed strategic partnerships with 75 countries around the world by the end of 2014 according to Chinese foreign minister Wang Yi. China's strategic partners range from developed to developing countries, from democratic to non-democratic countries, and from Western to Eastern countries. And in these strategic partnerships, China links itself with others on the basis of mutual complementarity, respect and reciprocity, following a relational thinking. The US on the other hand has made many "coalitions of willing" partners in addition to traditional military allies. These partners and allies share either common values or common interests with the US. More often than not, the US sees partnerships in other like-minded countries and rivalry or even enmity in other unlike-minded countries. As the Iraq war illustrated, the US has committed itself to democratizing Iraq before making it a friendly country, following a generic thinking.

In developing their bilateral relations, the contrast between the Chinese and American ways of thinking becomes even more visible. The China-US rapprochement and normalization of diplomatic relations in the 1970 s was made possible because, from the Chinese perspective, they could mutually benefit from their cooperation against the Soviet threat. From the American perspective, however, it was because China could be defined as a friend of the US when facing the Soviet threat, and "my enemy's enemy is my friend". China and the US were cast in the same category as enemies of the Soviet Union. This generic way of thinking stopped when the Soviet threat disappeared along with the collapse of the Soviet Union. And the US began to define China as a different "other", in particular after China's Tiananmen incident in 1989. Though it never sees the US as a like-minded friend or an unlike-minded enemy, China believes its relations with the US should return to normal for multiple reasons, as argued by Deng Xiaoping in the aftermath of the 1989 Tiananmen incident. China has since made numerous efforts to define ChinaUS relations in a positive way with such initiatives as "a strategic partnership" by President Jiang Zemin, "a proactive, cooperative and comprehensive relationship" by President Hu Jintao, and "a new type of major country relationship" by President $\mathrm{Xi}$ Jinping. Nonetheless, none of them has been well received by the US, which prefers to categorize China as either "a peer competitor" by President George W. Bush, or "a responsible stakeholder" by then Deputy Secretary of State Robert Zoellick, or "a partner in the group of two" by former national security adviser 
Brzezinski (2009). While it has generally accepted the American call to be "a responsible stakeholder" because this term helped define China's expected role in international affairs, China has bluntly rejected the idea of "G2" mainly because China does not see itself as in the same category as the US in any way. From a relational perspective, China puts emphasis on mutual respect as the cardinal virtue of its bilateral relations with the US. The US on the other hand, from a generic perspective, tends to identify China as either a friend or an enemy or something else in between.

\section{Weiqi: The Chinese Way of Gaming}

The Chinese relational way of thinking originates from their unique perceptions of Guanxi and it in turn impacts on the way that the Chinese shape, develop and change Guanxi. To explore China's behavioral codes in dealing with its foreign relations, we need to go beyond the Chinese way of thinking to the Chinese way of gaming by looking into the most telling games the Chinese play, such as Weiqi. According to anthropologists, games that people play are the earliest origin of human culture (Roberts, Arth and Bush 1959). Differences in cultures can be traced back to the differences in games played by different peoples (see, Huizinga 1955). Generally speaking, there are three prototypes of games in human history: strategic games, chance games and physical games, of which strategic games are the most relevant to players' strategic thinking and behaviors. They shape and thus reflect the methods that players follow to play board games and engage with each other in real life. Therefore, a particular strategic game serves as an important perspective to examine a nation's way of gaming only if this game has been played throughout the nation's history by its population. Weiqi is such a strategic game, played by the Chinese for more than 2000 years. As one of the world's oldest and most sophisticated board games, Weiqi is played between two opponents: each takes turns to place a 'stone' on a board with intersecting grids of $19 \times 19$ lines, and whoever controls a larger share of the board's territory will win the game. It has been widely perceived that Weiqi reflects the Chinese way of gaming just as Chess, as a different strategic game, signifies the Western way of gaming.

It has been very common for Chinese strategists to credit China's strategic thinking to the game of Weiqi, as well as to the Art of War by Sun Tzu. The guiding principles of Weiqi have been remarkably expressed by the central tenets in the Art of War. For example, the master player of Weiqi should clearly understand both the strengths and weaknesses of himself as much as those of his opponent on the board. This is strikingly similar to one of the most famous arguments of Sun Tzu: "So it is said that if you know your enemies and know yourself, you can win a hundred battles without a single loss. If you only know yourself, but not your opponent, you may win or may lose. If you know neither yourself nor your enemy, you will always endanger yourself." As further discussed below, the Chinese way of gaming in Weiqi and the Chinese strategic thinking revealed by the Art of War is very much consistent. Arguably, if one knows how to play Weiqi, it will be very easy to understand the Art of War, and vice versa. The Chinese thus strongly advocate 
studying Chinese strategies by understanding Weiqi, which is a crystallization of China's centuries-old gaming culture. For the Chinese, Weiqi is significant not just militarily, but also in the sense of philosophy, politics, society, and culture. David Lai, a Chinese American serving as faculty at the US Air War College, thus argues that "[T]his game bears striking resemblance to the Chinese way of war and diplomacy. Its concepts and tactics are living reflections of Chinese philosophy, strategic thinking, stratagems, and tactical interactions. This game, in turn, influences the way Chinese think and act" (Lai 2004. See also, Lai and Hamby 2002).

The idea that Weiqi is closely related to Chinese strategic thinking has been increasingly shared by Americans, particularly thanks to the unique contribution made by the US former Secretary of State and National Security Advisor Henry Kissinger. In his book, On China, Kissinger provided a strong endorsement to understanding the strategic thinking of the Chinese leadership by looking into Weiqi. Taking up Lai's enlightening discussions, Kissinger has interpreted China's foreign strategy as a strategy of Weiqi. For him, it was the Weiqi strategies of encirclement that Mao Zedong had exercised in China's fights against Japanese during World War II, against the US in the Korea War, and against the Soviet Union in their border disputes, etc. Scott Boorman is another American who has used the game of Weiqi to interpret China's behavioral code. In his book The Protracted Game: A Wei-Ch'i Interpretation of Maoist Revolutionary Struggle, published in 1969, Boorman connected strategic moves employed in Weiqi to the key decisions Mao made in order to ensure the victory of his campaign during the Chinese Civil War. He thus actually set a precedent in using Weiqi for the analysis of China's geopolitical strategies, both within and around its borders. As he put it, "It is safe to assume that, historically, there has probably been considerable interaction between the strategy of wei-ch'i and the strategy used in Chinese warfare. If indeed wei-ch'i and Chinese Communist Strategy are products of the same strategic tradition, weich'i may be more realistically used as an analogic model of that strategy than any purely theoretical structure generated by a Western social scientist" (Boorman 1971, 5-6).

By contrast, Chess could be presumed as a strategic game denoting the Western way of gaming. And as argued by Lai and Kissinger, among others, the difference between Chinese and Western strategies is easier to comprehend by looking into different strategic games they, respectively, play, i.e., Weiqi vs. Chess. For Lai, "In the American culture, many liken the American way of war and diplomacy to the games of chess (power-based fight), poker (bluffing and risk-taking), boxing (force on force), and American football (in many ways, resembles the American war machine)." American political and military leaders are familiar with those games, which "to a large extent reflect and in turn influence American culture, strategic thinking, and the American way of war" (Lai 2004). He took the US former National Security Advisor Brzezinski's thoughts in The Grand Chessboard: American Primacy and Its Geostrategic Imperatives as a prime example. Many aspects of the difference between Chess and Weiqi have been explored by Lai. For instance, he argued that "Chess is a game of power-based competition", while "Weiqi is a skill-based game". Consequently, Americans tend to place emphasis on 
capability and "pay more attention to the balance of military power in conflict situations" than the Chinese do. A Chess player focuses on what he "can achieve with limited resources" at his hands, whereas a Weiqi player thinks about what he "can bring to bear with additional resources". More importantly, "the philosophy behind Chess is to win decisively" by capturing the opposing king through "decimating whatever opposing forces are standing in the way". In Weqi, the underlying philosophy is "to compete for relative gain rather than seeking complete annihilation of the opponent forces". Therefore, Chess and Weiqi players have very different strategies to employ in games.

Kissinger also underscored the implications of different games that Chinese and Americans play for their divergent strategies. He admitted that the Chinese strategic doctrine is distinctly different from that of the West. For him, "Where the Western tradition prized the decisive clash of forces emphasizing feats of heroism, the Chinese ideal stressed subtlety, indirection, and the patient accumulation of relative advantage." And "this contrast is reflected in the respective intellectual games favored by each civilization" (Kissinger 2011, 23). Kissinger has also insightfully summarized different logics of Chess and Weiqi. For example, what Chess teaches people are the Clausewitzian concepts such as "center of gravity" and the "decisive point", while Weiqi teaches "the art of strategic encirclement". He agreed with Lai that the Chess player seeks total victory, whereas the Weiqi player aims for relative advantage. "Where the skillful chess player aims to eliminate his opponent's pieces in a series of head-on clashes, a talented Weiqi player moves into 'empty' spaces on the board, gradually mitigating the strategic potential of his opponent's pieces." So he concluded that "Chess produces single-mindedness; Weiqi generates strategic flexibility" (Kissinger 2011, 23).

There is plenty of evidence to show how Weiqi and Chess have, respectively, influenced the Chinese and American ways of gaming in their foreign relations in general and in their bilateral relations in particular. China as a Weiqi player usually takes a long-term and comprehensive view of its strategic interactions with the outside world including the US. It seeks relative advantage in a protracted campaign. It does not define its opponent as an enemy to be eliminated. And it will not deal with its opponent in a tit-for-tat approach, but live-and-let-live instead. By contrast, the US as a Chess player focuses on a short-term and case-by-case interactions with other international actors including China. It aims for a total victory in a decisive battle, respectively, in political, economic, military areas. It prefers to define its opponent as an enemy to be eliminated or checkmated. And it will deal with its opponent in a forceful way by preferably coercive means. In their strategic interactions, China and the US engage each other in the same game, which, more often than not, turns out to be different gaming to the two players. Even though they play together, China may play Weiqi with the US, while the US may play Chess with China. But, of course, the real picture in fact is more complicated, given that neither China nor the US is just a player of either Weiqi or Chess and that they are learning from each other about their respective gaming strategies through their interactions. Study of this topic lies beyond the scope of this paper and deserves specific academic endeavors that this author will do elsewhere. 


\section{Guanxi in Weiqi: Chinese Strategic Thinking}

Chinese strategic thinking is relational and lies behind the way to deal with various Guanxi in the process of strategy making and conducting. The making of strategy is a three-step process according to Layne (1997). They are: “determining a state's vital security interests; identifying the threats to those interests; and deciding how best to employ the state's political, military, and economic resources to protect those interests". Likewise, the conducting of strategy, as a process to employ a state's strategic means to handle strategic threats and achieve strategic goals, needs a state to prescribe the guiding principles, specify the key linchpins, and proscribe the counterproductive taboos. Those six aspects together provide us with telling clues about China's strategic thinking and gaming strategies. And they could be examined by looking into how the Chinese perceive and deal with major Guanxi in the game of Weiqi, though Weiqi resembles more bilateral than multilateral relations. The Chinese relational perceptions, preferences and logic of inference in Weiqi bespeak Chinese strategic thinking.

\subsection{Strategic Goals}

To begin with, a Weiqi player needs to deal with his opponent, Guanxi with whom is his key concern in the whole process of gaming. Even though each player without doubt wants to beat his opponent and win the game, the relationship between win and loss will be the first problem that they have to face, because the final outcome will not be a draw. As discussed above, a skillful Weiqi player aims for relative advantage instead of the total victory that the Chess player does. At the end of a well-matched game, the winner is always difficult to identify by untrained eyes because the relative advantage is probably very marginal. So no reasonable player will expect a landslide victory or defeat in a Weiqi game, unless there is clearly a big gap in skill between two players.

This kind of engagement is comparable to market competition, in which everyone wants a share, bigger or smaller, without denying a share for others. When defining its foreign policy goals, China has frequently exploited the wording of "win-win", "all-win", "mutual benefit", etc. For example, President Xi (2014) states that China "should promote neighborhood diplomacy, turn China's neighborhood areas into a community of common destiny, continue to follow the principles of amity, sincerity, mutual benefit and inclusiveness in conducting neighborhood diplomacy, promote friendship and partnership with our neighbors, foster an amicable, secure and prosperous neighborhood environment, and boost win-win cooperation and connectivity with our neighbors". A "live-and-let-live" game is at play (see, Su 2013). What the Chinese prefer to achieve is a relative advantage over their opponent no matter how slim the advantage is. As far as the strategic objective is concerned, the Chinese perception is relational and preference relative.

In its competition with the US in the region of Asia-Pacific, China does not expect to expel the American existence down to zero as many American people 
presume. A zero-sum game contradicts the Chinese mentality. But China does want to curb the negative American influence on China's national interests. That is why China has always argued that it welcomes the US to play a positive and constructive role in the Asia-Pacific region in various China-US official statements. In terms of the strategic goal, China aims to build, accumulate and maintain a relative advantage of shi vis-à-vis other countries including the US at regional level, and probably at global level as well. Shi is one of the best terms that are uniquely Chinese and better than any concepts in Western international relations theory to express Chinese strategic thinking. To simplify its definition, shi indicates a dynamic situation and the potential direction of development a player is positioned in. Since the Chinese also see shi as the most important factor determining the final result of a game, further discussions of this concept will follow below.

It its history, China has fought many wars in its home region, with both wins and losses as results. But China has never tried to eliminate any of its neighboring countries, or even take their land when China did win, for example in its 1962 war against India and 1979 war against Vietnam. What China has achieved by victory is a better and secured relative advantage of shi vis-à-vis its opponents, who might feel frustrated with a disadvantageous position for quite a long time. To serve this purpose, China does not favor after-victory occupation, which may give its opponents a chance to retaliate. On the other hand, if defeated, as in its war against Japan in 1894 for instance, China will suffer in a disadvantageous position for a very long time, with the tide of gaming not turned until 1945, when China won its war against Japan. Arguably, what the Chinese fight for is not just national interests, but relative advantage in shi.

\subsection{Strategic Threats}

Closely related to the win-loss issue, the second Guanxi in Weiqi is about the relationship between two players. They do not define each other as the enemy to be eliminated as in the game of Chess. Instead they take a neutral stand and do not see each other from a generic perspective as either enemies or friends, but respectful rivals at the least. Most of the time, a Weiqi player sees encirclement by his opponent as a threat. But, because the game itself is about encirclement and counterencirclement, he will see that threat as normal. And he will not expect to remove the encirclement as a way to remove the threat. With this being said, however, Weiqi players do regard some stones placed by their opponents as enemy acts and do whatever they could to curb or remove them because they might threaten the survival of their own stones. Here, a life-or-death struggle will be at play. But, for masters of Weiqi, even such a must-win fight should and could be avoided.

In its foreign relations, China goes a long way to refrain from defining states with which it has disputes entirely as enemies. Instead, China usually sees anti-China governments as enemies, or their specific anti-China behaviors as hostile. And at the same time China tries to differentiate anti-China people from those who are proChina in other countries. A relational rather than a generic logic of thinking is implicit in the Chinese way of defining the strategic threat. A "live-and-let-live" game is also at play. Here, the Chinese prefer to avoid naming any opponent as an 
enemy. For example, China does not define the US as an enemy and even does not see the American political system and ideology per se as threatening. But China does take as a strategic threat the US containment against China's rise and encircling China with its military engagement along China's borderlines. US hegemonism and efforts to Americanize its political values are also perceived as threatening to China. This way of strategic thinking partially explains why China does not favor making allies as the US does, since for the Chinese, you make enemies when you make allies. A partnership is thus a better option, lying between an alliance and an enmity (see, Chen 1999).

China, in particular in Mao's time, did see other countries around the world in a friend-enemy dichotomy and fought with several of its neighboring countries. But China's use of force in most cases stemmed from China's reactions for the purposes of survival and independence when its national security faced serious threat (e.g., the Korean War from 1950 to 1953) or when its sovereignty and territorial integrity encountered serious destruction (e.g., the China-India border war in 1962, the China-Soviet Union border conflict in 1969, and the China-Vietnam border war in 1979) while it had no alternative recourse. Such a life-or-death struggle, as a Weiqi player encounters when his opponent's stones pose a vital threat to his own stones, necessitates China's aggressive self-defense. But that scenario is more exceptional than normal. It is always what China tries her best to avoid.

Following the same logic of avoiding making enemies, China also refrains itself from Chinanizing other states. China's underlying way of thinking is that likemindedness is not a necessary precondition for two countries to make friends and that maintaining good Guanxi with other states is more appropriate and desirable than changing their domestic governance according to China's internal norms, as well as rules, laws, and institutions. This mind-set has been further strengthened after China adopted the European norm of sovereignty in the mid-nineteenth century. From China's perspective, diffusing internal norms is somewhat intrusive to the sovereignty of other states and is in breach of the principle of non-interference that China cherishes so much. While China prioritizes good Guanxi with other countries, it does not prefer to make them Chinanized by imposing its internal norms on them. China's position directly contradicts that of western countries, the EU for instance. The EU and its member states do not see keeping a good relationship with other states as more important than changing them into likeminded entities according to European norms. This mindset has been crucial in the process of European integration, which in turn encourages the EU to insist on this logic in developing its foreign relations. For the EU, national sovereignty has increasingly become a futile notion. Based upon their unique historical experience, Europeans have made efforts to re-conceptualize sovereignty (Pan 2010). They do not believe diffusing their internal norms violates the sovereignty of target states. Instead, they advocate the principle of humanitarian intervention as a replacement of non-interference. Europeans are thus very keen to Europeanize other states according to the norms of the EU. 


\subsection{Strategic Means}

When it comes to the strategic means, there are multiple Guanxi the Weiqi players need to deal with. It is not about how many resources one can put into the battle since they are basically the same and equal for the two players, but about how they could employ their resources more efficiently. To win the game, a better Weiqi player should know, among others,

- how to deploy his troops as his preferred strategy requires and how to break the opponent's deployment against his will;

- how to build, accumulate and use his own advantage of shi and weaken his opponent's;

- how to encircle the other side and break the encirclement by his opponent;

- how to make cost-benefit calculations in short term vs. long term;

- how and when to take a defensive posture or an offensive one;

- how to control and dominate the game when in an advantageous position and how to turn the battle's tide and snatch a victory out of defeat when in a disadvantageous position.

The Weiqi player's thinking about his own deployment is related to the deployment of his opponent, his own positional advantage or disadvantage of shi relative to his opponent's position, his own striving for encirclement compared to that of his opponent; his own cost and benefit compared to that of his opponent, his short-term concerns compared to his long-term considerations, his defensive posture compared to his offensive posture, his ability to control and dominate the game compared to his chance to change the tide of the battle, and so on and so forth. And a balance of options between two opposite extremes, or the so-called golden mean of the Confucian school, is preferred by most Weiqi players.

In China's conduct of foreign policies, Chinese perceptions about the strategic means are also relational and do not simply favor some options over other alternatives. More often, China uses its two hands to develop its Guanxi with other countries. The first and soft hand is cooperation, that is, to work with its opponent on the same issue and for the same purpose. The second and hard hand is struggle, that is, to do something against its opponent's will, making him uncomfortable, or even put him in trouble. For a long time, China has employed those two hands to deal with the US and Japan, for example. With regard to the US, China has made great efforts to build bilateral cooperation on economic interdependence, antiterrorism, non-proliferation, etc., in the post-Cold War era. Meanwhile, China has also confronted the US to protest its arms sales to Taiwan, receiving the Dalai Lama at a high level, and criticism of China's human rights record, etc. With Japan, China has maintained pretty good bilateral economic relations and the two countries have supported each other in the process of regionalization. But, after the Japanese government "nationalized" the Diaoyu/Senkaku islands, which are in dispute between China and Japan, China has resorted to its hard hand to establish real control of those islands and strengthen its sovereignty claims in the East China Sea by dispatching its maritime patrol vessels and surveillance aircrafts to the 
surrounding waters and skies in a regular way and by declaring an Air Defense Identification Zone covering that area (Pan 2013).

When using its soft hand, China explicitly requires or implicitly expects reciprocity. From the Chinese perspective, reciprocity means not necessarily equality of exchanges, but equal standing and mutual respect in the process of exchange. So China does not worry whether the two sides will equally benefit from bilateral trade as much as the US does. This is the case even when China suffers from a trade deficit, as with many ASEAN countries for example. When using its hard hand, China will try to avoid confronting its opponent in a tit-for-tat way. China's space in Asia has been squeezed by the US with its "pivot" or "rebalancing" strategy, and the corresponding Trans-Pacific Partnership initiative, in which China detected a strong implication of containment (Ross 2012). But, China does not simply opt for a countering approach. Instead, China on the one hand continues to reassure the US, as well as other countries around the globe, that it will stick to its path of peaceful development, reiterating that it will strive to build "a new type of major country relationship" with major powers, in particular the US, in order to avoid repeating the historic tragedy of great power politics. At the same time, China has made attempts to pioneer the new space being left as a geopolitical superpower vacuum. China's most interesting initiatives in this regard are "the Belt and Road Initiative": the "Silk Road Economic Belt" and the "Maritime Silk Road". China turns its eyes westward to develop its own shi by offering its neighboring countries economic benefits and sharing the Chinese dream of national rejuvenation with them. While, with the establishment of the Asian Infrastructure Investment Bank, China provides Asian countries with alternatives to the US-led TTP, China does not make them choose sides between China and the US. To some extent, every country including the US can opt for China's initiatives, and China for American ones. This is not to create "a world without the West" as highlighted by some Americans (Barma et al. 2014). Instead, it provides a typical "tit-not-for-tat" solution, underlain by Chinese strategic thinking on gaming.

\subsection{Strategic Principles}

The process of strategy making and conducting is not a one-way street. Since a national strategy is made and conducted in strategic interactions with other states, it must allow enough flexibility. As players in the game of Weiqi, strategic actors should always bear in mind the guiding principles to follow, the key cornerstones to count on, and the gaming taboos to stay away from.

From a Guanxi perspective, a Weiqi player needs to differentiate one game from another, even when against the same player, and one opponent from another in different games. So the general guiding principle could be termed as a contingent adaptation. A brilliant Weiqi player knows how to take and maintain initiatives when in a favorable position and, when otherwise, how to turn the tide on the board to his favor. This requires him to be able to adapt himself to dynamic situations, including the shifting balance of positions between two players, the changing strategy of his opponent, the unexpected and irregular moves of the other side, and even any mistakes made by his opponent and himself alike, etc. On the other side of 
the same coin, this also requires him to be able to create situations that force his opponent to react in a passive way. As Sun Tzu puts it, "those skilled at making the enemy move do so by creating a situation to which he must conform". Sun Tzu also emphasizes that "If your opponent is of choleric temper, seek to irritate him. Pretend to be weak, that he may grow arrogant. If he is taking his ease, give him no rest. If his forces are united, separate them. Attack him where he is unprepared, appear where you are not expected." Those tactics are not just about strategic deception, but more about strategic flexibility and adaptation. A winning strategy in Weiqi as in a real war should be adaptable to and contingent on the ever-changing circumstance.

Facing the end of the Cold War and China's difficult situation in the international arena after the Tiananmen incident, Deng proposed a tenet of "Taoguang Yanghui and Yousuo Zuowei" (keeping a low profile and getting something accomplished) as the guiding principle of China's foreign strategy. This tenet may seem selfcontradictory to international observers, but it is congruous to Chinese foreign policy makers. And it allows China to be flexible in moving the center of gravity from the first part of the phrase to the second or the other way around, depending on China's perceptions of its changing position vis-à-vis other countries in the international system. A contingent adaptation is thus favored by the Chinese in their strategic thinking. It is arguably true that China's strategy from a perspective of this guiding principle is not a real strategy in the strict sense of this term as defined by the West. It is actually a non-strategy.

China's insistence on the non-interference principle is also contingent, being dictated by China's dynamic national interest and power, primary concern with regime security and legitimacy, and changing identity and strategic thinking (Pan and $\mathrm{Du} 2015)$. Even though the non-interference principle has not been abandoned, the way in which it is applied has changed. As a result of compromises China's application of the non-interference principle is becoming more inflexible at one end of the spectrum and more flexible at the other, the result being that China's foreign policies shift back and forth between the two extremes. Sovereignty and regime security are arguably the most decisive factors that force China to maintain the noninterference principle. When they are at stake, China will apply the non-interference principle rigidly, unless there are available alternative ways to make a concession, which will then lead to a somewhat flexible application. If what is at stake are national interests other than sovereignty and regime security China can usually find alternatives to make a concession, meaning that China will invoke the noninterference principle in a more flexible and pragmatic way. In this general pattern, the most important aspect is China's defense against interference in its own internal affairs, the second one is China's self-restraint from interfering in the internal affairs of other sovereign states, and thirdly it is China's opposition to the intervention of a third party state in another third party state's internal affairs.

\subsection{Strategic Linchpins}

The key cornerstones that a Weiqi player should count on to win a game include strategy and shi, both of which are relational. A game of Weiqi is in nature a game 
of strategy. One major difference between Weiqi and Chess is that the Weiqi board is empty before players take turns to place stones, while troops are positioned in a fixed default way on the chessboard. Strategic planning is a must for a Weiqi player before he places the very first stone and it must be comprehensive, long term and flexible. A better strategy is the guarantee of a final victory. And here "better" is defined by effectiveness in comparison. No matter how well or poorly designed a strategy may look, it is a good strategy only if it helps a player to achieve his intended goals, and it is a better one only if it helps a player in the game of Weiqi, for example, to lead in initiatives and force his opponent to follow by passive reactions, in other words to create a favorable shi that empowers him to maneuver rather than being maneuvered (Mott and Kim 2006). As explored by Sun Tzu in his Art of War, shi signifies a static configuration of an overall structure on the one hand and a dynamic major tendency and momentum on the other. He contends that shi lies in running water and rolling stones and can wash away anything standing in their way. Shi, which can be best described as a type of "strategic advantage", is intangible and potential, only visible to well trained strategists. In Weiqi, only by relying on a more favorable shi can a player secure final victory. A game of Weiqi is a continuous competition for shi. So a master of Weiqi usually has many alternative options of winning strategy and knows which to choose and how to change it during games in order to create and maintain a favorable shi vis-à-vis his opponent. In Weiqi, it is impossible and unnecessary to seek a favorable balance of power, because the overall resources that the two players can devote to the Weiqi game do not favor any one, and the balance of power in specific battles on the board varies, which may favor one player in one corner and favor another in another corner. The final defining factor to win or lose in Weiqi is shi, which is power-based but more implicative than the balance of power per se can show.

Chinese leaders prefer to look at the world and China's position in it from a comprehensive and long-term perspective before they make or change China's foreign strategies. In the late 1980s, it was Deng's reinterpretation of the world's main theme as "peace and development" (Deng 1993, 104-106) that led China's strategy to shift from "being prepared for war" to opening-up and reform. The initiation of opening-up and reform also helped China to change its statecraft from going against shi to following shi. Deng proposed "Taoguang Yanghui and Yousuo Zuowei" as China's guiding principle of foreign relations and the "cat" ("white or black, it is a good cat if only it can capture mice") and the "crossing the river (by touching the stones)" theories concerning national development, all of which was creatively carried out by following generations of Chinese leadership to write the Chinese story of peaceful rise. Rising by following shi, rather than going against it, becomes China's most important historical experience (Pan 2012).

Thanks to its recent achievement of peaceful rise, China was winning shi when the 2008 global financial crisis broke out. And the crisis in turn further pushed China into a comparatively more favorable position. China acquired a fresh important historic opportunity to open a new chapter for its peaceful rise story due to its relative advantage in economic growth, accelerated process of multipolarization in the international system, increasing expansion of China's international influence, and positive change in international views towards China. The 
Chinese thus perceived a subtle shifting of shi among major powers in the world in favor of China. In the aftermath of the 2008 global financial crisis, Yang (2010) offered a broad remapping of the power shift in the world with his theory of "Four Groups of Shi", among which major emerging countries make a group of gaining shi; the United States belongs to a group of defending shi; the EU, Japan and Russia constitute a group of losing shi; and many developing countries in their difficulties are fighting for their shi. Even though it is hard to justify a major shift in the global balance of power, it makes sense to argue that international relations is regrouping countries according to their possession of shi instead of power. In international competition, China puts emphasis on a relative superiority in strategy and a comparative advantage in shi against its opponents.

\subsection{Strategic Taboos}

In Weiqi, a player must try to avoid counterproductive moves that earn him a little only to cost him a lot. There are many gaming taboos, such as nearsightedness, greediness and impatience. It is nearsighted if a player just focuses on a battle at a part of the board forgetting the whole picture of the game or on a short-term gain or loss without considering its long-term consequences. A greedy player prefers offense to defense and thus is easily lured to be entangled in a probably unnecessary tit-for-tat fight that leads him to lose more then he gains. Impatience could overtake a player when he is clearly in either a favorable or unfavorable situation. For the former, he may become impatient to ensure a bigger victory as quickly as possible. As a result, he might lose his relative advantage in shi and even the game. For the latter, he tends to be impatient and eager to turn the losing momentum around. That might further push him into a more unfavorable position in the balance of shi. A smart player must be coolheaded to resist temptations that might make him nearsighted, greedy and impatient. Those taboos are related to a major Guanxi that is easily overlooked in Weiqi, i.e., how a player faces himself. As argued by Sun $\mathrm{Tzu}$, in a real war a strategic player needs to know himself as he knows his enemy.

To avoid a little gain at the expense of a great loss, China always stresses the overall and long-term development of its relations with other states. For example, when former Chinese Premier Wen (2004) gave an official definition of the ChinaEU comprehensive strategic partnership, he said, "comprehensive" means that the cooperation should be all-dimensional, wide-ranging and multi-layered. It covers economic, scientific, technological, political and cultural fields, contains both bilateral and multilateral levels, and is conducted by both governments and nongovernmental groups; "strategic" means that the cooperation should be long term and stable, bearing on the larger picture of China-EU relations. It transcends the differences in ideology and social system and is not subjected to the impacts of individual events that occur from time to time; "partnership" means that the cooperation should be equal-footed, mutually beneficial and win-win. The Chinese preference favors farsightedness in developing China's foreign relations.

China has also attempted to be generous and patient. One relevant example here is how China has dealt with its territorial disputes with its neighboring countries in the post-Cold War period. Generally speaking, China has gone out of its way to 
settle its border disputes with its neighbors on notably generous terms. As Taylor Fravel once put it, in settling 17 of its 23 territorial disputes China usually agreed to take less than half of the contested land (Fravel 2005. See also, Fravel 2008). It is unimaginable, from a Chess perspective, that China would agree to give up parts of its territorial claims when it increasingly became more powerful with ever-growing military strength. But, it is quite understandable from a Weiqi perspective because the Chinese are clear that if every disputant wants a lion's share of the disputed territory there will be no solution and that by giving up some territorial interests China has harvested not only stable and secure borders, but also friendly Guanxi with its neighbors.

That said, however, little progress has been made in the settlement of the maritime disputes over the China seas. Instead, with patience, China has been adopting a policy of "shelving the disputes and working for joint development" in the hope that acceptable solutions to conflicting sovereignty claims could be found in the future. From a Weiqi perspective, China has good reasons to be reluctant to make the same sacrifice in maritime disputes as it did in land border disputes in order to arrive at peaceful solutions. As Fravel demonstrates, unlike territorial disputes involving land territories, offshore islands are "cheap for the claimants to dispute, requiring few troops to maintain a claim", and therefore "states are most likely to adopt a delaying strategy to maximize the potential economic and strategic benefits" (Fravel 2005). More than that, the disputed islands are not as divisible as the disputed land. Losing some islands in the China seas will lead China to lose a great deal of $s h i$, which is not the case in the border disputes. So China will not be as generous in maritime disputes as in land border disputes. However, China's maritime territorial claims are not greedy ambitions that are derived from its improved position in the international system. China's claims have nothing to do with China's rising power. China, weak or strong, has always sought to defend its sovereignty over the claimed islands, including Taiwan.

\section{Conclusion}

The Chinese way of strategic thinking is relational and best exemplified in the game of Weiqi. China's most preferable strategy in its foreign relations is to employ a combination of various means to achieve good and stable Guanxi with other countries without defining any of them, or being defined by any of them, as an enemy. The Chinese tend to take a long-term and overall perspective, and equal Guanxi to interests, or sometimes even put Guanxi above interests. But China is unwilling to give up its position in the balance of shi vis-à-vis other countries. An upper hand in shi is more desirable than a bigger share of interests from the Chinese perspective.

An American style grand strategy is not suitable for China. Due to their divergent ways of strategic thinking, a specifically defined strategic goal, prioritized strategic threats according to enmity, and a plentiful selection of tit-for-tat options as strategic means, as found in an American grand strategy are almost all not applicable to China. China's preference for a favorable shi is hard to specify. China 
is not inclined to group other states according to a friend-enemy dichotomy. China does not favor tit-for-tat solutions to problems in its foreign relations. To some extent, the US is not a good example that China should learn from in its strategy making and conducting.

Instead, China's foreign strategy should be loosely defined. China does need a grand strategy, without which China's strategic behaviors will lose vision and direction. But China's grand strategy should be mainly defined in terms of its principles, linchpins and taboos, rather than its goals, threats and means. A flexible and pertinent grand strategy for China should keep ambiguity on its strategic goals, threats and means on the one hand, and clarity on its strategic principles, linchpins and taboos on the other. A principle of contingent adaptation free from tit-for-tat, a linchpin of a favorable balance of $s h$, and a vigilance against strategic nearsightedness, greediness and impatience will make China's grand strategy truly Chinese.

Acknowledgments This research is funded by China's Ministry of Education Research Project "A Study on China-US Strategic Interactions" (10JJDGJW008) chaired by the author. The author is grateful to Zhimin Chen, Lizhu Fan, Thomas Gold, Xiaoying Qi, participants of the conference "The Field of Guanxi Studies" in Berkeley March 2015, and anonymous reviewers of this journal for their valuable comments.

\section{References}

Barma, Naazneen, Ely Ratner and Steven Weber. 2014. Welcome to the World Without the West. The National Interest Online. http://nationalinterest.org/feature/welcome-the-world-without-the-west11651. Accessed 12 Nov 2014.

Boorman, Scott. 1971. The protracted game: a Wei-Ch'I interpretation of maoist revolutionary strategy. London: Oxford University Press.

Brzezinski, Zbigniew. 2009. The group of two that could change the world. Financial Times, January 13, 2009.

Chen, Zhimin. 1999. Huoban Zhanlue: Shiji zhijiao Zhongguo de Xianshi Lixiang Zhuyi Waijiao Zhanlue [Partnership diplomacy: China's realistic idealistic diplomacy strategy at the Turing of the century]. Taipingyang Xuebao [Pacific Journal] 3: 12-20.

Chiu, Liang-hwang. 1972. A cross-cultural comparison of cognitive styles in Chinese and American children. International Journal of Psychology 7(4): 235-242.

Deng, Xiaoping. 1993. Deng Xiaoping Wenxuan [Selected works of Deng Xiaoping], volume III (1982-1992). Beijing: Renmin Chubanshe [People's Press].

Emirbayer, Mustafa. 1997. Manifesto for a relational sociology. The American Journal of Sociology 103(2): 281-317.

Fei, Xiaotong. 1985. Xiangtu Zhongguo [Rural China]. Shanghai: Shanghai Sanlian Shudian [Shanghai Sanlian Press].

Fravel, Taylor. 2005. Regime insecurity and international cooperation: explaining China's compromises in territorial disputes. International Security 30(2): 46-83.

Fravel, Taylor. 2008. Strong borders, secure nation: cooperation and conflict in China's territorial disputes. Princeton: Princeton University Press.

Gold, Thomas, Doug Guthrie, and David Wank. 2002. An introduction to the study of Guanxi. In Social connections in china: institutions, culture, and the changing nature of Guanxi, ed. Thomas Gold, Doug Guthrie, and David Wank. Cambridge: Cambridge University Press.

He, Kai, and Huiyun Feng. 2012. Debating China's assertiveness: taking China's power and interests seriously. International Politics 49: 633-644.

Huizinga, Johan. 1955. Homo Ludens: a study of the play-element in culture. Boston: Beacon Press.

Johnston, Alastair Iain. 1995a. Cultural realism: strategic culture and grand strategy in Chinese history. Princeton: Princeton University Press.

Johnston, Alastair Iain. 1995b. Thinking about strategic culture. International Security 19(4): 32-64. 
Johnston, Alastair Iain. 2013. How new and assertive is China's new assertiveness? International Security 37(4): 7-48.

Kissinger, Henry. 2011. On China. New York: The Penguin Press.

Lai, David, and Gary Hamby. 2002. East meets west: an ancient game sheds new light on US-Asian strategic relations. Korean Journal of Defense Analysis 14(1): 247-275.

Lai, David. 2004. Learning from the stones: a go approach to mastering China's strategic concept, shi. Carlisle: Strategic Studies Institute, US Army War College.

Layne, Christopher. 1997. From preponderance to offshore balancing: America's future grand strategy. International Security 22(1): 86-124.

Liang, Suyin. 1987. Zhongguo Wenhua Yaoyi [Essentials of the Chinese culture]. Xianggang (Hong Kong): Sanlian Shudian Xianggang Fendian [Sanlian Press in Hong Kong].

Matsuda, Yasuhiro. 2014. How to understand China's assertiveness since 2009: hypotheses and policy implications. Center for strategic and international studies: Strategic Japan Working Paper.

Mott, William, and Jae Chang Kim. 2006. The philosophy of Chinese military culture-shih vs li. New York: Palgrave Macmillan.

Nisbett, Richard. 2003. The geography of thought: how asians and westerners think differently ... and why. New York: Free Press.

Pan, Zhongqi, and Ping Du. 2015. The logic of contingency in China's insistence on the non-interference principle. Fudan Journal of the Humanities and Social Sciences 8(4): 597-615.

Pan, Zhongqi. 2010. Managing the conceptual gap on sovereignty in China-EU relations. Asia Europe Journal 8(2): 227-243.

Pan, Zhongqi. 2012. Cong Suizhi dao Moushi: Zhongguo de Guoji Quxiang yu Zhanlue Xuanze [From following the Shi to shaping the Shi: China's international orientation and strategy]. Shanghai: Fudan Daxue Chubanshe [Fudan University Press].

Pan, Zhongqi. 2013. Standing up to the challenge: China's approach to its maritime disputes. ISPI Analysis 184: 1-9.

Qin, Yaqing. 2009. Guanxi benwei yu guocheng jiangou: jiang zhongguo linian zhiru guoji Guanxi lilun [Relationality and processual construction: bringing Chinese ideas into international relations theory]. Zhongguo Shehui Kexue [Social Sciences in China] 3: 5-20.

Roberts, John, Malcolm Arth, and Robert Bush. 1959. Games in culture. American Anthropologist 61(4): 597-605.

Ross, Robert. 2012. The problem with the pivot. Foreign Affairs 91(6): 70-82.

$\mathrm{Su}$, Changhe. 2013. Gongsheng xing guoji tixi de keneng [The possibility for a symbiotic international system]. Shijie Jingji yu Zhengzhi [World Economy and Politics] 9: 2-22.

Wen, Jiabao. 2004. Vigorously Promoting Comprehensive Strategic Partnership between China and the European Union. Speech at the China-EU Investment and Trade Forum, Brussels, 6 May 2004.

Womack, Brantly. 2008. China as a normative foreign policy actor. In Who is a normative foreign policy actor? The European Union and its global partners, ed. Nathalie Tocci. Brussels: Centre for European Policy Studies.

Xi, Jinping. 2014. Xi eyes more enabling int'l environment for China's peaceful development. http://en. people.cn/n/2014/1130/c90883-8815967-3.html. Accessed 30 Nov 2014.

Yang, Jiemian. 2010. Lun 'Sishi Qunti' he Guoji Liliang Chongzu de Shidai Tedian [Four groups of shi and the features of contemporary regrouping of international forces]. Shijie Jingji yu Zhengzhi [World Economy and Politics] 3: 4-13.

Zhongqi Pan is Professor of International Relations at the School of International Relations and Public Affairs, Fudan University. He is the author of A Theoretical Interpretation of International Politics (Shanghai: Shanghai People's Publishing House, 2015); From Following the Shi to Shaping the Shi: China's International Orientation and Strategy (Shanghai: Fudan University Press, 2012); The Logic to Live with the Hegemony: American Strategies and China-US Security Relations in the Post-Cold War Period (Shanghai: Shanghai People's Publishing House, 2012); World Order: Structure, Mechanisms, and Models (Shanghai: Shanghai Publishing House, 2004). He is editor of Conceptual Gaps in China-EU Relations: Global Governance, Human Rights and Strategic Partnerships (Basingstoke, U.K.: Palgrave Macmillan, 2012). He has published many articles both in Chinese and in English in various academic periodicals. 